\title{
Adana Acıbadem Hastanesinde Hastane Enfeksiyonları Surveyansı: Bir Yıllık Analiz Sonuçları
}

\author{
Barbaros Şahin Karagun ${ }^{1} \odot$, Özay Akyıldız² ${ }^{\oplus}$, Hilal Onaç ${ }^{3} \odot$, Fadime Kaya ${ }^{4} \odot$,

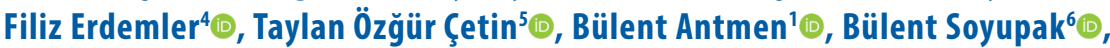 \\ Emre Alhan ${ }^{7}$ (])
}

'Acıbadem Üniversitesi, Çocuk Hematoloji Onkoloji ve Kit Ünitesi, Adana, Türkiye 2Acıbadem Adana Hastanesi, Enfeksiyon Hastalıkları, Adana, Türkiye

${ }^{3}$ Acıbadem Adana Hastanesi, Mikrobiyoloji, Adana, Türkiye

${ }^{4}$ Acıbadem Adana Hastanesi, Hemşirelik Hizmetleri, Adana, Türkiye

${ }_{5}^{5}$ Acıbadem Adana Hastanesi, Anestezi ve Yoğun Bakım, Adana, Türkiye

${ }^{6}$ Acıbadem Adana Hastanesi, Üroloji,

Adana, Türkiye

${ }^{7}$ Acıbadem Adana Hastanesi, Çocuk Enfeksiyon Hastalıkları, Adana, Türkiye

Barbaros Şahin Karagun, Dr. Öğr. Üyesi Ozay Akyıldız, Dr.

Hilal Onaç, Dr.

Fadime Kaya, Hemşire

Filiz Erdemler, Hemşire

Taylan Özğür Çetin, Dr.

Bülent Antmen, Prof. Dr.

Bülent Soyupak, Prof. Dr.

Emre Alhan, Prof. Dr.
Illetişim:

Dr. Öğr. Üyesi Barbaros Şahin Karagun Acıbadem Üniversitesi, Çocuk Hematoloji Onkoloji Ve Kit Ünitesi , Adana , Türkiye Tel: +90 5062345145

E-Posta: barbaros.karagun@acibadem.com
Gönderilme Tarihi : 07 Kasım 2018

Revizyon Tarihi : 12 Mart 2019

Kabul Tarihi : 05 Mayıs 2019
ÖZET

Amaç: Hastanemizde gelişen hastane enfeksiyonuna (HE) neden olan etkenlerin dağıımı ve antibiyotik duyarlııılarının belirlenmesi.

Hastalar ve yöntem: Yaklaşık 116 yatak kapasiteli hastanemizde, 0cak 2017 - Aralık 2017 tarihleri arasındaki hastane enfeksiyonları surveyans yöntemi ile retrospektif olarak değerlendirildi.

Bulgular: 0cak 2017-Aralık 2017 tarihleri arasında Acıbadem Adana Hastanesinde 9931 hasta yatısıı yapıldı. Hastaların 92'sinde hastane enfeksiyonu geliştiği saptandı. Tüm hastane genelinde enfeksiyon hızı \%1,32 idi. HE dağılımı; 30 hastada bakteriyemi $(\% 29,4), 22$ hastada cerrahi alan enfeksiyonu $(\% 21,5), 20$ hastada üriner sistem enfeksiyonu $(\% 19,6)$ ve 15 hastada pnomoni $(\% 14,7)$ olarak saptandı.

Çocukluk yaş grubunda bakteriyemi ve pnömoni, yetişkin yaş grubunda ise üriner sistem ve cerrahi alan enfeksiyonu en sık saptanan HE idi. HE gelisen hastaların \% 97,7 'de bir ya da daha fazla etken izole edilirken, $\% 2,3$ 'de herhangi bir etken izole edilemedi. Hastane genelinde en sık izole edilen mikroorganizmalar sırasılla; Klebsiella spp. $(\% 29,5)$, E.coli $(\% 22,7)$, maya mantarları $\% 20$ , 5 ve S.aureus $(\% 9)$ idi. HE en sık olarak onkoloji servisinde $(\% 57,8)$, genel yoğun bakım ünitesinde $(\% 24,5)$ ve pediatrik kemik iliği ünitesinde $(\% 17,6)$ görüldü.

Sonuçlar: HE yataklı tedavi kurumlarının hizmet kalitesinin önemli göstergelerinden biri olup artık tüm dünyada önemli bir sağ lık sorunu olarak görülmektedir. HE önlemek için düzenli olarak surveyans çalıșmaları yapılarak elde edilen sonuçlar düzenli bir şekilde takip edilmeli, ayrıca gereksiz invaziv işlemlerden kaçınılmalıdır. Tüm hastaneler ve hastane içinde birimlerin; hastane enfeksiyonuna neden olan mikroorganizmaları ve bunların direnç oranlarını surveyans çalışmaları ile belirlemeleri, tedavi kararlarını buna göre vermeleri gerekir.

Anahtar sözcükler: Surveyans, hastane enfeksiyonu

\section{A SURVEILLANCE OF HOSPITAL-ACQUIRED INFECTIONS IN ADANA ACIBADEM HOSPITAL: ONE YEAR ANALYSIS RESULTS ABSTRACT}

Purpose: We aimed to determine the antibiotic susceptibility and distribution of factors leading to hospital-acquired infections in our hospital.

Patients and Methods: In our hospital with a capacity of approximately 116 beds, hospital-acquired infections between January 2017 and December 2017 were evaluated retrospectively by the surveillance method.

Results: 9931 patients were hospitalized in Acibadem Adana Hospital between January 2017 and December 2017. Hospitalacquired infections (HAl) have been detected in 92 patients. The infection rate in the hospital was $1.32 \%$. The ratio of HAI was determined as bacteremia in 30 patients $(29.4 \%)$, surgical site infection in 22 patients $(21.5 \%)$, urinary tract infection in 20 patients $(19.6 \%)$, and pneumonia in 15 patients (14.7\%).

The two most common HAl in the pediatric age group were bacteremia and pneumonia while the urinary tract and surgical site infection were common in the adult age group. One or more agents were isolated in $97.7 \%$ of patients with HAl, while no agents were isolated in $2.3 \%$ of patients. The most common microorganisms isolated in the hospital were Klebsiella spp. (29.5\%), E.coli $(22.7 \%)$, Yeasts $20.5 \%$ and S.aureus $(9 \%)$, respectively. HAI was mostly seen in oncology service $(57.8 \%)$, general intensive care unit (24.5\%) and pediatric bone marrow unit (17.6\%).

Conclusion: HAl is one of the most important indicators of the service quality of inpatient treatment institutions/centers and is seen as an important health problem all over the world. All hospitals and units should determine the flora and resistance rate of their patient profile by surveillance studies. Besides, treatment decisions should be given accordingly. Surveillance studies should be performed to prevent $\mathrm{HAl}$ and the results should be monitored regularly. Also, unnecessary invasive procedures should not be allowed.

Keywords: Surveillance, nosocomial infection 
astane enfeksiyonları (HE) diğer bilinen adıyla nozokomiyal enfeksiyonlar son zamanlarda sağlık hizmeti ve bakımı alan hastalarda gelişen enfeksiyonlar olması nedeni ile sağlık bakımı ilişkili enfeksiyonlar (health care associated infections) olarak da bilinmektedir (1-3). Tüm önlemlere rağmen halen tüm dünyada en önemli mortalite ve morbidite artışı sebeplerinden biri olup hastanede yatış süresinin uzaması ve tedavi maliyetini arttırması açısından da önemli sağlık sorunlarından biri haline gelmiştir. Hastane enfeksiyonları yatakı tedavi kurumlarının sunmuş oldukları tedavi hizmeti kalitesini en önemli dolaylı göstergelerinden biridir. Mortalitesi ve maliyeti çok yüksek olmasına rağmen önlenebilir bir enfeksiyon olması, enfeksiyonların kontrolü ve akılcı antibiyotik kullanım politikalarının belirlenebilmesi açııından da son derece önemlidir (1-5).

HE kontrolü, her hastanede mevcut olan hastane enfeksiyon kontrol birimleri tarafından yapılan surveyans sonuçIarının takip edilmesi, bu sonuçların diğer hastanelerin enfeksiyon oranlarıyla karşılaştırılması ve etkin enfeksiyon kontrol önlemlerinin alınması ile mümkündür. Yapılan farklı çalışmalarda tüm dünyada HE görülme sıklığı ortalama \%3,1-14,1 arasında değişirken bu oran ülkemizde çocukluk yaş gurubu içeren çalışmalarda \%1,3-16 olarak saptanmıştır. Hastane enfeksiyonlarını sağlıklı ve objektif olarak değerlendirebilmek için, mutlaka standart tanımlamaları ve enfeksiyon hız/oran parametrelerini kullanmak gerekir. Tüm dünyada bu tanımlamalar için "Centers for Disease Control and Prevention (CDC)" tarafından geliştirilen kılavuzlar kullanılmaktadır (1-8).

Bu çalışmada; Acıbadem Adana Hastanesinde yatan hastalarda bir yıllık süre içinde gelişen hastane enfeksiyonlarının sıklığı, tipi ve sorumlu etkenlerin belirlenebilmesi için CDC kriterleri esas alınarak araştııı Iması amaçlanmıştır.

\section{Gereç ve Yöntem}

Bu çalışma, Ocak - Aralık 2017 tarihleri arasında Tıbbı Onkoloji, Pediatrik Hematoloji-Onkoloji ve Kemik Illiği Nakil Ünitelerini (KIT) içeren 116 yataklı Acıbadem Adana Hastanesi'nde yapıldı. Bir yıl içerisinde hastaneye yatan hastalarda gelişen hastane enfeksiyonları, kültüre dayalı surveyans yöntemi ile retrospektif olarak incelendi. Hastane enfeksiyonlarının takibi, kaydı ve incelenmesi enfeksiyon kontrol komitesi tarafından yürütüldü.

Hastane enfeksiyonu geliştiği düşünülen tüm hastalardan; kan kültürü ve enfeksiyon odağı olduğu düşünülen bölgelerden (idrar, balgam, beyin-omurilik sıvısı, boğaz, trakea, yara yeri, kateter, göbek) kültür örnekleri alındı. Üreme olan kültürlerdeki mikroorganizmaların identifikasyonu, Acıbadem Adana Hastanesi Mikrobiyoloji Laboratuvarı'nda konvansiyonel yöntemler kullanılarak yapıldı. Kültür sonucunda üreme saptanan bütün hastalar, CDC kriterleri kullanılarak hastane enfeksiyonu açısından değerlendirildi. Kontaminasyon ve kolonizasyon olduğu düşünülen kültür sonuçları çalışma dışında bırakıldı.

HE olduğu kabul edilen hastalara, HE izlem formları (yaş, cinsiyet, altta yatan hastalık, invaziv girişim varlığı ile profilaktik antibiyotik kullanımını sorgulayan) dolduruldu. Veriler toplandıktan sonra, tüm servis ve yoğun bakım üniteleri için enfeksiyonun türü, etken mikroorganizmalar ve bu mikroorganizmaların antibiyotik ve/veya antifungal duyarlıık sonuçları değerlendirildi. İstatistik analizlerinin hesaplanmasında Windows paket programı kullanıldı.

\section{Bulgular}

Çalışmamızda 92 hastada hastane enfeksiyonu geliştiği ve bu hastaların $37(\% 40,3)$ 'sinin kadın, $55(\% 59,7)$ 'inin erkek olduğu belirlendi. Hastaların yaşları 10 gün ile 92 yaş arasında değişmekte olup ortalama yaş $32 \pm 3,9$ yıl idi. Gelişen enfeksiyonların dağılmı Şekil 1'de belirtilmiştir. Bakteriyemi ve pnömoni çocukluk yaş grubunda en sık rastlanan $\mathrm{HE}$ iken, yetişkin yaş grubunda ise üriner sistem ve cerrahi alan enfeksiyonu idi. Olguların \%2,3'ünde herhangi bir etken izole edilemedi.

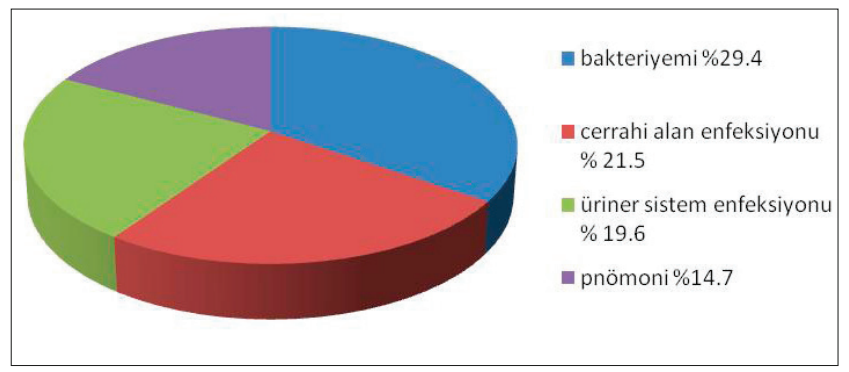

Şekil 1. Hastane Enfeksiyonlarının dağıım sıklığı

HE'nun birimlere göre dağılımına bakıldığında, en sık yetişkin ve çocuk onkoloji hastalarını içeren onkoloji servisinde $(\% 57,8)$, genel yoğun bakım ünitesinde $(\% 24,5)$ ve pediatrik kemik iliği ünitesinde $(\% 17,6)$ geliştiği saptandı (Şekil 2). Cerrahi alan enfeksiyon hızı ise \%1,2 olarak saptandı. Cerrahi alan enfeksiyonu, en sık kalp damar cerrahisi 5 (\%50), ardından ortopedi 3 (\%30) ve beyin sinir cerrahisi 2 (\%20) birimlerinde görüldüğü tespit edildi. Genel yoğun bakım enfeksiyon hızı \%2,36, en sık görülen $\mathrm{HE}^{\prime}$ nun 
alt solunum yolu enfeksiyonu (\%50), üriner sistem enfeksiyonu $(\% 37,5)$ ve primer kan dolaşım enfeksiyonu $(\% 12,5)$ olduğu belirlendi. Yenidoğan yoğun bakım ünitesinde ise enfeksiyon hızı \%1,1 olarak tespit edildi.

Hastane genelinde en sık izole edilen mikroorganizmalar sırasılyla Klebsiella spp. $(\% 29,5)$, E.coli $(\% 22,7)$, S.aureus (\%9) iken, maya mantarları \%20,5 oranında izole edildi (Şekil-3). Cerrahi alan enfeksiyonlarında en sık S.aureus (\%20), üriner sistem enfeksiyonlarında E.coli (\%50), primer kan dolaşımı enfeksiyonlarında ise Klebsiella spp. $(\% 29,6)$ ve Candida spp $(\% 29,6)$ etken olarak saptandı. İzole edilen gram negatif bakteriler arasında, genişletilmiş spektrumlu beta-laktamaz (GSBL) pozitifliği, E.coli suşlarında \%60, Klebsiella spp. suşlarında ise $\% 53,8$ olarak bulundu.

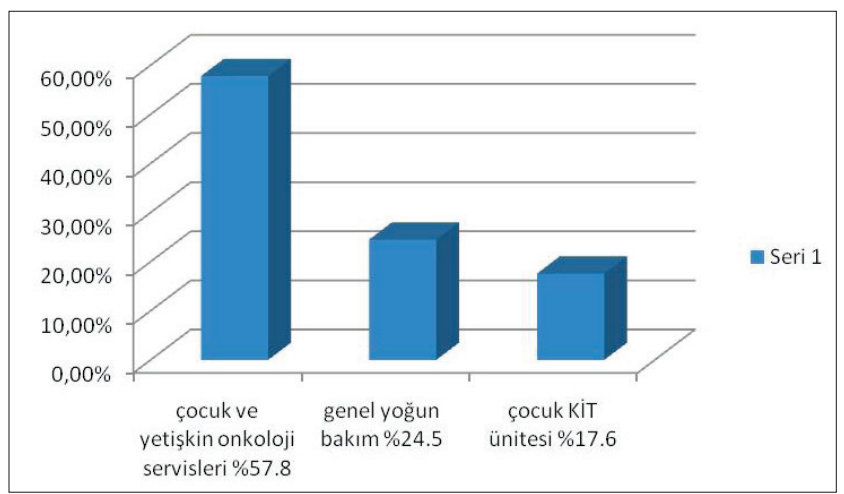

Şekil 2. Hastane Enfeksiyonlarının birimlere göre dağılımı

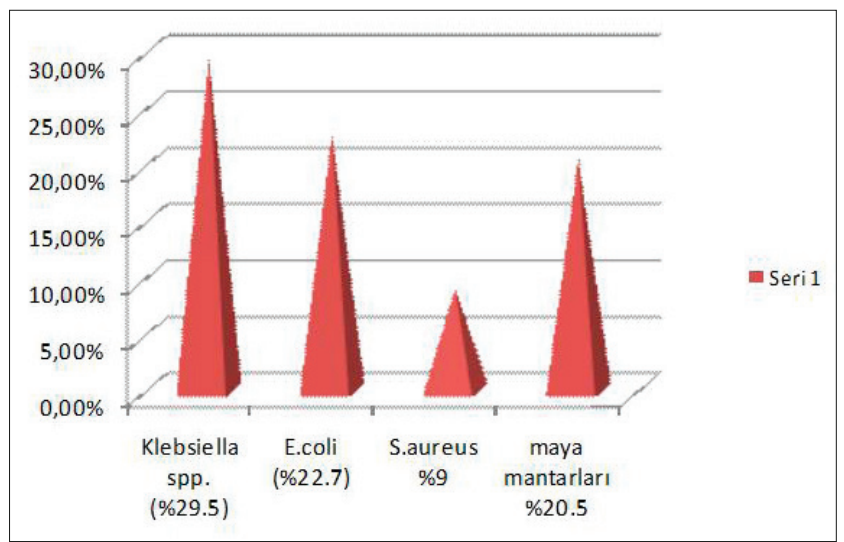

Şekil 3. Hastane Enfeksiyonuna sebep olan etkenler.

Antibiyotik direnç oranları değerlendirildiğinde, Klebsiella spp.'de karbapenem direnci \%46,1, Pseudomanas spp.de ise bu oran $\% 8$ olarak saptandı. Enterococcus spp.'de vankomisin direnci (VRE) \%83,7 iken, S.aureus suşlarında metisilin direnci $\% 75$ olarak belirlendi. Cerrahi alan enfeksiyonlarının $\% 87,7$ ' sinde (\%71,4 yüzeyel, $\% 14,3$ derin ve $\% 14,3$ 'de organ boşluk), üriner sistem enfeksiyonlarının tümünde etken izole edildi. HE gelişen hastaların \%84,7'sinde enfeksiyon gelişimini kolaylaştıran bir ya da daha fazla invaziv girişim öyküsü mevcuttu. Genel yoğun bakım ünitesinde, santral kateter ilişkili kan dolaşım enfeksiyonu \%1,8 iken kateter ilişkili üriner sistem enfeksiyonu \%3,3 olarak saptandı. Tüm bunların yanı sıra hastane genelinde el hijyeni uygunluk oranı $\% 90,7$ idi.

\section{Tartışma}

$\mathrm{HE}$, yüksek morbidite ve mortalitenin yanı sıra tedavi harcamalarında artışa sebep olmaları nedeniyle hem ülkemizde hem de tüm dünyada son yıllarda en önemli sağlık sorunlarından biri olmuştur. Bu nedenle, hastane verilerinin toplanması, dökümantasyonu, analizi ve yorumlanması sağlanarak hastane enfeksiyonu surveyansı tanımlanmış böylece, HE daha dikkati çeker bir hal almıştır. Elde edilen bu surveyans verileri, hastane enfeksiyonlarının kontrolünde doğru ve uygun politikaların belirlenmesinde en önemli bilgi kaynağını sağlamaktadır.

Hastaya ve hastadan elde edilen laboratuvar sonuçlarına göre yapılan surveyans çalışmalarında, $\% 60-90$ oranında HE saptanırken sadece laboratuvara dayalı olarak yapılan çalışmalarda bu oran \%30-70 arasında değişmektedir. Bu nedenle farklı hastanelerin HE açısından kıyaslaması yapılırken sadece hastane enfeksiyon hızlarının hesaplama yöntemlerinin aynı olması yeterli olmayacaktır. Aynı zamanda, hastanenin hizmet basamağının, personel sayısının, personele verilen hastane enfeksiyonu konusunda eğitim ve uygulamaların ve yatak kapasitesinin, yoğun bakım varlığı gibi fiziki koşullarında benzer olması gerekir $(1,4-8)$.

HE riskini artıran faktörler arasında, hastaya ait faktörler, yapılan invaziv girişimler ve çapraz kontaminasyonlar yer alır. Özellikle genel ve cerrahi yoğun yoğun bakım üniteleri ve kemik iliği nakil ünitelerinde hayat kurtarmak amacıyla yapılan invaziv işlemlerin (mekanik ventilasyon, üriner kateterizasyon, santral venöz kateter vb.) hastane enfeksiyonu gelişim oranlarını artırdığı yapılan çok sayıda çalışma ile gösterilmiştir. Kullanılan antibiyotiklere direnç gelişiminin önlenmesi için en önemli stratejinin, gereksiz antibiyotik kullanımı sınırlayarak enfeksiyon kontrol uygulamalarına uyumun artırılması olduğu bilinmektedir $(1,4,9-13)$.

Genel olarak, tüm dünyada hastane enfeksiyonları \%5-10 oranında görülürken ülkemizde bu oran \%1,35-16,6 arasında değişmektedir. Hastanemizde de 2017 yılında HE hızı \%1,32 olarak saptanmıştır. Bu oran tüm dünya ve 
ülkemiz verileri ile uyumlu olmakla birlikte hastaneye ait fiziksel ve sosyal nedenlerden ötürü bir başka hastane ile karşılaştırmanın çok doğru olmayacağını düşünmekteyiz. Ayrıca bu düşük oranı; serviste hastayı takip eden klinisyenin kültür alma stratejisi, uygun kültürün alınmaması, alınan kültürün doğru çalışılmaması gibi faktörlerin etkilediğini ve aslında daha yüksek olabileceğini düşünüyoruz.

Yetişkin ve çocuk yaş grubu arasında hastane enfeksiyonları açısından önemli farklılıklar vardır. Genel olarak HE hızı çocuklarda yetişkinden daha fazladır. Ayrıca çocukluk yaş grubunda $\mathrm{HE}$ ile yaş arasında da ters bir iliş̧i olduğu bilinmektedir. Çocukluk yaş grubunda özellikle çocuk yoğun bakım ve yenidoğan yoğun bakım ünitelerinde daha sık ilaç uygulanması, çocuk kateterlerinin stabilizasyonun daha zor olması, daha sık hemşire bakımı ve manipülasyonlarının varlığı HE sıklığını artırmaktadır. Yetişkin yaş grubunda üriner enfeksiyonlar daha sık görülürken, çocuk yaş grubunda kan akımı enfeksiyonları daha sık görülmektedir. Bizim çalışmamızda da çocukluk yaş grubunda hastane enfeksiyonu olarak en sık bakteriyemi ve pnömoni görülür iken yetişkin yaş grubunda üriner sistem ve cerrahi alan enfeksiyonu görülmüş olup yapılan çalışmalarla benzer sonuçlara ulaşılmaktadır (1, 4-6, 11-15).

Hastane enfeksiyonuna sebep olan patojenlerin varlığı ve sıklığı ülkeler, hastaneler, hatta aynı hastane içinde birimler arasında bile önemli farklılıklar göstermektedir. Sıklıkla izole edilen patojenler arasında, gram pozitif bakteriler (S.aureus) ve gram negatif bakteriler (E.coli, pseudomonas ve klebsiella türleri) ve maya mantarları yer almaktadır. Son dönemlerde yapılan çalışmalarda fungal enfeksiyonların sıklığının giderek artmaktadır (13-17).

Hastanemiz genelinde en sık izole edilen bakteriler daha önce yapılmış çalışmalara benzer bir şekilde, Klebsiella spp. $(\% 29,5)$, E.coli $(\% 22,7)$ daha az oranda S.aureus $\% 9$ idi. Ancak literatürden farklı olarak hastanemizde hastane enfeksiyonu etkeni olarak $\% 20,5$ oranında maya mantarları izole edildi. Bu yüksek oran hastanemizde yetişkin ve

\section{Kaynaklar}

1. Hacımustafaoğlu M, Celebi S, Tuncer E, Özkaya G, Çakır D, Bozdemir ŞE. Çocuk Kliniği ve Çocuk Yoğun Bakım Ünitesi Hastane Enfeksiyonları Sıklığı. J Pediatr Inf 2009;3:112-7. http://www.cocukenfeksiyondergisi. org/upload/documents/200903/112-117.pdf

2. Özçetin M, Saz EU, Karapınar B, Özen S, Aydemir Ş, Vardar F. Hastane Enfeksiyonları; Sıklı̆̆ı ve Risk Faktörleri. J Pediatr Inf 2009;3:49-53. http://www.jpi-turkey.org/upload/documents/200902/49-53.pdf

3. Dossaji S, Çelik Ü, Alhan E, Yıldızdaş D, Ünal İ. Nozokomiyal Enfeksiyonlar için Enfeksiyon Belirteçleri. J Pediatr Inf 2008;2:12-8. http://www.cocukenfeksiyondergisi.org/upload/ documents/200801/12-18.pdf çocuk hematoloji onkoloji servisleri ve kemik iliği nakil ünitelerinin varlığına bağlı olabileceği gibi bölgemizin coğrafik nedenleri ile de uyumlu olarak yüksek saptandığını düşünmekteyiz.

Çalışmamızda E.coli suşlarında genişletilmiş spektrumlu beta-laktamaza direnci (GSBL) \%60 iken, Klebsiella spp.'de GSBL direnç oranı $\% 53,8$ ve karbapenem direnci $\% 46,1$ idi. S.aureus metisilin direnci (MRSA) \%75 ve Pseudomanas spp.de karbapenem direnci \%0 olarak saptandı. Yapılan diğer çalışmalarla karşılaştııılığında direnç oranlarının daha düşük olduğu görüldü (11-18).

Doğum ve bölgesel sorunlar nedeniyle ortaya çıkan mecburi göç sonucu artan nüfus sayısı, etki eden mikroorganizmalardaki değişiklik, yapılan invaziv ve cerrahi müdahaleler ve bunların sonucunda ortaya çıkan HE bağlı artan mali yük konunun önemini giderek daha da artırmaktadır. Her birim, hastane ve ülke genelinde düzenli surveyans çaıışmaları ile enfeksiyon sıklığını belirlemek, gelişen hastane enfeksiyonlarının tedavisinde ve önlenmesinde gerekli olan verileri sağlaması açısından son derece önemlidir.

Sonuç olarak, hastane enfeksiyonları tüm dünyada önemli bir sağlık sorunu olup, bu sorun giderek daha da artan bir problem haline gelmektedir. HE önlemek için düzenli olarak surveyans çalışmaları yapılarak sonuçlar düzenli bir şekilde takip edilmeli, gereksiz invaziv işlemlere izin verilmemeli ve işi biten kateterler mümkün olduğunca erken çıkartılmalıdır. Hastane genelinde el hijyeni uyumunun arttırılması, uygunsuz antibiyotik kullanımının önüne geçilmeli, izolasyon önlemlerinin alınmasına dikkat edilmeli, ve aseptik uygulamalara özen gösterilmelidir. Ayrıca enfeksiyon sebebi olan etkenlerin izole edilerek uygun antibiyotik başlanması ve gereksiz antibiyotik kullanımının önlenmesi gerekir. Tüm hastaneler ve hastane içindeki birimler kendi hasta profilindeki bakteriyel florasını ve direnç oranlarını surveyans çalışmaları ile belirlemeli, tedavi kararlarını bu direnç oranlarını göz önünde bulundurarak vermeleri gerekmektedir.

4. Özer-Balın Ş, Aktaş-Şenol A. Yoğun Bakım Ünitesinde Gelişen Hastane Infeksiyonlarının Değerlendirilmesi. Klimik Derg 2017;30:108-13. [CrossRef]

5. Bakır M, Soysal A. Pediatrik Hastalarda Nozokomiyal İnfeksiyon Kontrolü. Turkiye Klinikleri, Pediatri (Özel Sayı) 2004;2:318-26.

6. Aşcıoğlu S. Hastane enfeksiyonları. Türk Hij Den Biyol Derg 2007;64:1-3. https://www.journalagent.com/Turkhijyen/Pdfs/ Thdbd_64_Sup_Er-1_1_3.Pdf

7. Ertek M. Hastane Enfeksiyonları Türkiye Verileri. İ. Ü. Cerrahpaşa Tıp Fakültesi Sürekli Tıp Eğitimi Etkinlikleri. Sempozyum Dizisi No:60 Ocak 2008. s. 9-14. http://www.ctf.edu.tr/stek/pdfs/60/6001.pdf 
8. Wagenlehner FEM, Naber KG, Çek M. Nozokomiyal Enfeksiyonlar. Turkiye Klinikleri J Urology 2004;1:112-20.

9. Uslu S, Bolat F, Can E, Comert S, Nuhoğlu A. Yenidoğan Yoğun Bakım Ünitelerinde Hastane Enfeksiyonlarını Önleme Çalışmaları. Bakırköy Tıp Derg 2010;6:1-7. http://cms.galenos.com.tr/Uploads/ Article_23828/BTD-6-1.pdf

10. Ersoy $Y$, Fırat M, Kuzucu Ç, Bayındır Y, Şenay Karaaslan Ş, Bilişik G, But AD. İnönü Üniversitesi Tıp Fakültesi Hastanesinde Hastane İnfeksiyonları. İnönü Üniversitesi Tıp Fakültesi Derg 2003;10:133-7. https://docplayer.biz.tr/4496259-Inonu-universitesi-tip-fakultesihastanesinde-hastane-infeksiyonlari.html

11. Saçar S, Kavas ST, Asan A, Cevahir N, Serin S, Turgut H. Pamukkale Üniversitesi Hastanesinde Hastane İnfeksiyonları Surveyansı: üç yıllık analiz. Turk J Infect 2008;22:15-21.

12. Çelik I, Şenol A, Karlıdağ GE, İnci NA. Fırat Üniversitesi Hastanesi 2006 Yılı Hastane Enfeksiyonları Surveyans Sonuçları. Fırat Tıp Derg 2009;14:242-6. http://www.firattipdergisi.com/pdf/pdf_FTD_598. pdf

13. Tüfek A, Tekin R, Tuba Dal T, Tokgöz O, Doğan E, Kavak GÖ, Salih Hoşoğlu S. Reanimasyon ünitesinde on yıllık sürede gelişen hastane enfeksiyonlarının değerlendirilmesi ve literatürün gözden geçirilmesi. Dicle Med J 2012;39:492-8. [CrossRef]
14. Karahocagil MK, Yaman G, Göktaş U, Sünnetçioğlu M, Çıkman A, Bilici A, et al. Hastane Enfeksiyon Etkenlerinin ve Direnç Profillerinin Belirlenmesi. Van Tıp Derg 2011;18:27-32. https://www. journalagent.com/vtd/pdfs/VTD_18_1_27_32.pdf

15. Artan C, Oğuzkaya Artan M, Baykan Z. Sağlık Personelinin Sağlık Riskleri ve Hastane Enfeksiyonları ile İlgili Bilgi Düzeyleri ve Uygulamaları. Düzce Üniversitesi Sağlık Bilimleri Enstitüsü Derg 2015;5:6-11. http://static.dergipark.org.tr/article-download/ imported/5000071154/5000111283.pdf?

16. Anıl BA, Anıl M, Özdemir NÖ, Bayram N, Bal ZŞ, Köse E, et al. Çocuk Yoğun Bakım Ünitesinde Hastane Enfeksiyonu Risk Faktörleri. J Pediatr Emerg Intens Care Med 2014;1:9-16. http://cms.galenos. com.tr/Uploads/Article_11515/9-16.pdf

17. Yüceer $\mathrm{S}$, Demir SG. Yoğun bakım ünitesinde nozokomiyal enfeksiyonların önlenmesi ve hemşirelik uygulamaları. DicleTıp Derg 2009;36:226-32. http://static.dergipark.org.tr/article-download/ imported/5000104231/5000097353.pdf?

18. Akın A, Esmaoğlu Çoruh A, Alp E, Günay Canpolat D. Anestezi Yoğun Bakım Ünitesinde Beş Yıl içerisinde Gelişen Nozokomiyal Enfeksiyonlar ve Antibiyotik Direncinin Değerlendirilmesi. Erciyes Tıp Derg 2011;33(1):007-016. https://www.journalagent.com/ erciyesmedj/pdfs/EMJ_33_1_7_16.pdf 